\title{
IFN $\beta$ secreted by microglia mediates clearance of myelin debris in CNS autoimmunity
}

\author{
Magdalena Kocur ${ }^{1 \dagger}$, Reiner Schneider ${ }^{2 \dagger}$, Ann-Kathrin Pulm ${ }^{1 \dagger}$, Jens Bauer ${ }^{1}$, Sonja Kropp ${ }^{1}$, Michael Gliem², \\ Jens Ingwersen ${ }^{2}$, Norbert Goebels ${ }^{2}$, Judith Alferink ${ }^{3,4}$, Timour Prozorovski ${ }^{2}$, Orhan Aktas ${ }^{2+}$ and Stefanie Scheu ${ }^{1{ }^{*+}}$
}

\begin{abstract}
Introduction: Multiple sclerosis (MS) is a chronic demyelinating disorder of the central nervous system (CNS) leading to progressive neurological disability. Interferon $\beta$ (IFN $\beta$ ) represents a standard treatment for relapsing-remitting MS and exogenous administration of IFN $\beta$ exhibits protective effects in experimentally induced CNS autoimmunity. Also, genetic deletion of IFN $\beta$ in mice leads to an aggravation of disease symptoms in the MS model of experimental autoimmune encephalomyelitis (EAE). However, neither the underlying mechanisms mediating the beneficial effects nor the cellular source of IFN $\beta$ have been fully elucidated.

Results: In this report, a subpopulation of activated microglia was identified as the major producers of IFN $\beta$ in the CNS at the peak of EAE using an IFN $\beta$-fluorescence reporter mouse model. These IFN $\beta$ expressing microglia specifically localized to active CNS lesions and were associated with myelin debris in demyelinated cerebellar organotypic slice cultures (OSCs). In response to IFN $\beta$ microglia showed an enhanced capacity to phagocytose myelin in vitro and up-regulated the expression of phagocytosis-associated genes. IFN $\beta$ treatment was further sufficient to stimulate association of microglia with myelin debris in OSCs. Moreover, IFNß-producing microglia mediated an enhanced removal of myelin debris when co-transplanted onto demyelinated OSCS as compared to IFN $\beta$ non-producing microglia.

Conclusions: These data identify activated microglia as the major producers of protective IFN $\beta$ at the peak of EAE and as orchestrators of IFNß-induced clearance of myelin debris.
\end{abstract}

Keywords: IFNß, Microglia, CNS autoimmunity, Multiple sclerosis, EAE

\section{Introduction}

Multiple sclerosis (MS) is an inflammatory demyelinating disease of the central nervous system (CNS). More than 20 years ago, interferon $\beta$ (IFN $\beta$ ) became the first immunomodulatory substance used in the treatment of MS. IFN $\beta$ is currently the most commonly used therapy for relapsing-remitting MS (RRMS), reducing relapses and severity of disease $[1,2]$. Genetic ablation of IFN $\beta$ or its receptor leads to an increased severity of experimental autoimmune encephalomyelitis (EAE) [3,4] a mouse model exhibiting clinical, neuropathological, and immunological disease manifestations of MS [5]. Conversely, induction of endogenous IFN $\beta$ by poly $(\mathrm{I}: \mathrm{C})$ stimulation suppresses EAE, confirming its protective role in CNS autoimmunity [6]. Today, neither the cellular source of

\footnotetext{
* Correspondence: stefanie.scheu@hhu.de

${ }^{\dagger}$ Equal contributors

${ }^{1}$ Institute of Medical Microbiology and Hospital Hygiene, Medical Faculty, University of Duesseldorf, Universitaetsstr. 1, 40225 Duesseldorf, Germany Full list of author information is available at the end of the article
}

type I IFN in EAE nor its localization relative to responding cells is known due to a lack of sufficiently sensitive in situ tools.

Also, the exact mechanisms underlying the protective effects of IFN $\beta$ remain incompletely understood. Various IFN $\beta$-mediated modes of action have been suggested, including (i) downregulation of matrix metalloproteinase 9 thereby reducing tissue damage and inflammation, (ii) prevention of effector cell migration by downregulating the adhesion molecule very late antigen-4 (VLA-4) $[7,8]$, (iii) downregulation of MHC II molecules on antigen presenting cells combined with upregulation of the inhibitory PD-L1 and PD-L2 ligands [9,10], (iv) inhibition of $\mathrm{T}$ cell proliferation [11], (v) the induction of immune cell apoptosis [12] and (vi) most recently the induction of FoxA $1^{+} \mathrm{T}$ regulatory cells [13]. Removal of myelin debris has been suggested as an essential protective mechanism ameliorating IFN $\gamma$-mediated neuroinflammation by downregulating the transcription levels of pro-inflammatory factors like TNF, IL-1 $\beta$, or iNOS [14]. 
Reducing inflammation by enhancing phagocytosis efficacy may therefore represent a novel therapeutic approach in the treatment of neuroinflammation as observed in MS. Until now, however, a direct role for IFN $\beta$ in phagocytosis of myelin or axonal debris has not been shown and the functional consequences of microglial phagocytosis remain largely unexplored.

Though IFN $\beta$ was shown to delay disease progression, adverse side effects such as depression, flu-like symptoms, skin reactions, and bone marrow suppression have limited its use [15]. Also, IFN $\beta$ treatment is not always effective, as about $30 \%$ to $50 \%$ of patients experience breakthrough disease. One reason is production of neutralizing antibodies to IFN $\beta$ resulting in reduced or complete loss of therapeutic efficacy [16]. Moreover, there is the risk that a long term systemic "block" of inflammation could affect the elicitation of immune responses required for host defense. Therefore, it is of great interest to identify the cellular source and define the mechanisms associated with IFN $\beta$-mediated protection against neuroinflammation as a first step in the development of cell-specific treatment regimes.

In this study we characterized the cell type responsible for IFN $\beta$ production and its impact on microglia effector functions in EAE using a yellow fluorescent protein (YFP) IFN $\beta$ reporter mouse model, organotypic slice cultures, and adult microglia cell cultures. We demonstrate that microglia are the primary IFN $\beta$ producing cells during the peak phase of EAE. We further show that IFN $\beta$ induces localization of microglia in close proximity to myelin debris and subsequently increases microglial phagocytotic activity. These findings and the fact that IFN $\beta$-producing microglia orchestrated the clearance of myelin debris in organotypic cerebellar slice cultures reveal a so far unknown function of IFN $\beta$. Our data further suggest that future IFN $\beta$-based therapies targeting these cells in the CNS can be developed for treatment of demyelinating CNS disorders.

\section{Materials and methods}

\section{Mice and EAE induction}

Female C57BL/6 N mice were purchased from Charles River. IFN $\beta^{\mathrm{mob} / \mathrm{mob}}$ (messenger of IFN beta: IFN $\beta /$ YFP reporter mouse) [17], IFN $\beta^{-1-}$ [18] and IFNAR1 ${ }^{-1-}$ [19] mice were backcrossed for at least 10 generations onto C57BL/6 N background. PLP-EGFP mice were used for indicated organotypic slice culture experiments [20]. All mice were housed under specific pathogen free conditions in the animal research facility of the University of Duesseldorf. Mice at 6-12 weeks of age were used for all experiments. Active EAE was induced by tail-base immunization with $200 \mu \mathrm{g}$ of $\mathrm{MOG}_{35-55}$ (Biotrend) in complete Freund's adjuvant (CFA), supplemented with Mycobacterium tuberculosis H37RA (10 mg/ml) (Difco
Laboratories) and $200 \mathrm{ng}$ pertussis toxin (Sigma) on 0d and $2 \mathrm{~d}$. A control group was treated with CFA only and $200 \mathrm{ng}$ pertussis toxin on $0 \mathrm{~d}$ and $2 \mathrm{~d}$. Classification of disease progression: 0 no paralysis; 0.5 partial paralysis of tail; 1.0 paralysis of tail; 1.5 unilateral paralysis of hind legs; 2.0 bilateral paralysis of hind legs; 2.5 bilateral paralysis of hind legs with unilateral weakness of forelegs; 3 tetraparesis (abort criteria); 4 death. All animal experiments were approved by the government of North Rhine-Westphalia (Az.: 84-02.04.2013.A466, Az.: 8.87-50.10.34.08.241).

\section{Organ and CNS mononuclear cell isolation}

Mice were anesthetized and thereafter perfused with $50 \mathrm{ml}$ ice cold PBS. For qRT PCR and flow cytometric analysis spleen, spinal cord and brain were removed. For flow cytometric analysis spinal cord and brain were homogenized and digested with collagenase/dispase (Roche) followed by DNase I (Roche) digestion. CNS derived mononuclear cells were isolated from the $30 \% / 70 \%$ interface of a Percoll gradient after centrifugation at $800 \times \mathrm{g}$ for $25 \mathrm{~min}$ at room temperature. For RNA isolation organs were isolated after perfusion with $50 \mathrm{ml} \mathrm{PBS}$ and quickfrozen in liquid nitrogen.

\section{Antibodies}

We used monoclonal Antibodies against murine CD11b (M1/70), CD86 (GL-1), CD45 (104) from BD Biosciences, CD16/CD32 (2.4G2) from eBioscience for FACS analysis. Antibodies used for the OSC, spinal cord and brain histology: rat-MBP (1:500) from Millipore, rabbit-Iba1 (1:500) from WAKO Chemicals, mouse-Neurofilament (NF-M) (1:1000) from Convance Laboratories Inc., giunea pigGFAP (1:1000) from SYnaptic Systems, rat-CD68 (1:500) from BioLegend, rat-Mac3 (1:500) from BioLegend, ratTLR3 (1:500) from BioLegend, rb-pIRF7 (1:400) from Bioss-Antibodies and rabbit-CCR2 (1:500) from BiossAntibodies and rtLAMP2 (1:400) von BioLegend. A polyclonal crossreacting anti-GFP antibody was purchased from Abcam. Biotin conjugated donkey-anti-rabbit, as well as normal sera from mouse, rat and donkey were purchased from Jackson Immuno Research. All secondary antibodies conjugated with fluorophores (Cyanine Dye $\mathrm{Cy} 2, \mathrm{Cy} 3$ and $\mathrm{Cy} 5$ ) were purchased from Life Technologies and used in a dilution of 1 to 500 .

\section{Flow cytometry and cell sorting}

Co-expression of indicated cell surface markers with YFP expression was analyzed on a FACS Canto II (Becton Dickinson). Cells were pregated as DAPI'. Isolated CNS mononuclear cells or primary adult microglia were sorted on a FACS Aria cell sorter (Becton Dickinson) for CD11b and CD45 and YFP reporter allele expression. RNA isolation of ex vivo sorted primary 
microglia was performed with the mirVana miRNA isolation kit (Ambion Inc). RNA isolation of in vitro sorted primary adult microglia was performed with RNA isolation kit (Fluka).

\section{Intracerebroventricular injection}

Mice were anaesthetized with isofluran and placed in a stereotactic frame. The skull was exposed and trepanated for injection of $6 \mu \mathrm{g}$ poly (I:C) (Amersham) into the lateral ventricle. The bregma coordinates were AP: $-0.3 \mathrm{~mm}$, $\mathrm{ML}:+1.0 \mathrm{~mm}$, and DV $-3.0 \mathrm{~mm}$.

\section{Cell culture}

For primary adult microglia culture CNS mononuclear cells were isolated from brain and spinal cord of 4-6 week old mice under sterile conditions and cultured in VLE-DMEM (Biochrom) with 10\% FCS, $50 \mu \mathrm{M} \beta$-ME and $15 \%$ of M-CSF containing supernatant from L929 cells. The protocol was adapted from Ponomarev [21]. Cells were stimulated on d14 with $50 \mu \mathrm{g} / \mathrm{ml}$ poly (I:C),

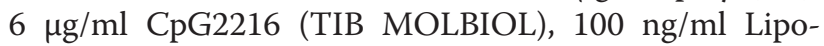
polysaccharide (LPS) from Salmonella minnesota R595 (List Biological Laboratories, Inc.), $1 \mu \mathrm{g} / \mathrm{ml}$ Pam3CSK4 (Invivogen) or $100 \mathrm{U} / \mathrm{ml}$ mouse recombinant IFN $\beta$ (R\&D Systems) for $6 \mathrm{~h}$ or $24 \mathrm{~h}$ as indicated or analysis of phagocytosis capacity was performed with DII-coupled myelin isolated according to Norton and Poduslo [22].

Mouse BV2 cells [23,24] were maintained on uncoated petri plates in Dulbecco's modified Eagle's medium (DMEM) (Invitrogen) supplemented with Glucose (4.5 g/l), 10\% FCS (Invitrogen), $20 \mathrm{mM}$ GlutaMAX (Life Technologies) and penicillin/streptomycin $(5 \mu \mathrm{g} / \mathrm{ml})$ (Life Technologies). Media was changed every 2 days and cells were passaged at a confluence of $80-90 \%$ performing trypsinization (Invitrogen).

\section{Immunofluorescence of microglial cells}

Primary microglia or BV2 cells were once washed with PBS, fixed with 4\% PFA for 15 minutes and again washed 2 times with PBS. Cells were blocked for $1 \mathrm{~h}$ with $5 \%(\mathrm{v} / \mathrm{v})$ horse serum (Sigma Aldrich) in $0.5 \%(\mathrm{v} / \mathrm{v})$ Triton X-100 in PBS. Primary antibodies were diluted in $2.5 \%(\mathrm{v} / \mathrm{v})$ horse serum, $0.25 \%(\mathrm{v} / \mathrm{v})$ Triton X-100 in PBS and incubated overnight at $4{ }^{\circ} \mathrm{C}$. After three times washing for 5 minutes with $0.1 \%(\mathrm{v} / \mathrm{v})$ Triton X-100 in PBS the cells were incubated with fluorescent secondary antibodies, diluted in $2.5 \%(\mathrm{v} / \mathrm{v})$ horse serum, $0.25 \%(\mathrm{v} / \mathrm{v})$ Triton X-100 in PBS, for $1 \mathrm{~h}$ at RT. Cells were counterstained with Hoechst (Life Technology) and mounted on glass slides with Immuno Mount (DABCOTM).

\section{RNA isolation, CDNA synthesis and qRT-PCR}

RNA was isolated with RNA isolation Kit (Fluka or Macherey-Nagel). Purified RNA was digested with DNase
I (Roche) to remove trace contaminating genomic DNA. An aliquot corresponding to $0.5-3 \mu \mathrm{g}$ of purified RNA was used for first-strand cDNA synthesis using Superscript III reverse transcriptase and oligo (dT) in a final volume of $20 \mu \mathrm{l}$ according to the manufacturer's instruction (Invitrogen Life Technologies). cDNA was used for subsequent PCR. Real-time quantification of genes was performed using a SYBR Green RT-PCR assay (Applied Biosystems, USA). Briefly, each $20 \mu \mathrm{l}$ SYBR green reaction consisted of $5 \mu \mathrm{l}$ cDNA, $10 \mu \mathrm{l} \mathrm{SYBR}$ Green PCR-mix (2×), $1 \mu \mathrm{l}$ forward and reverse primer $(5 \mathrm{pM})$ and $4 \mu \mathrm{l}$ distilled water. PCR was performed with the following cycling conditions: 40 cycles of $10 \mathrm{sec}$ at $95^{\circ} \mathrm{C}, 60 \mathrm{sec}$ at $60^{\circ} \mathrm{C}$ and a separate dissociation step. Specificity of the PCR product was confirmed by examination of the dissociation reaction plots. A distinct single peak indicated only one DNA sequence was amplified during the RT-PCR. The samples were run in duplicates and the level of expression of each gene was compared with the expression of GAPDH. Amplification, detection of specific gene products and quantitative analysis were performed using an "ABI 7500" sequence detection system (Applied Biosystems, USA).

\section{Organotypic slice cultures}

Organotypic slice cultures (OSCs) were generated from 10 days old mice as described before [25]. The cerebellum was cut into $400 \mu \mathrm{m}$ thick slices using a McIllwain tissue chopper (GaLa Instrumente). OSC were dissociated in ice-cold dissecting medium (Hank's Balanced Salt Solution (HBSS), Life Technologies) complemented with penicillin/streptomycin (100 U/ml, Life Technologies), $2.5 \mathrm{mg} / \mathrm{ml}$ glucose (Sigma Aldrich) and $10 \mathrm{mM}$ kynurenic acid (Sigma Aldrich). OSCs were cultured on Millicell$\mathrm{CM}$ culture plate inserts (Millipore) in culture medium (50\% (v/v) MEM, 25\% (v/v) HBSS, 25\% (v/v) heatinactivated horse serum, $2 \mathrm{mM}$ glutamine, penicillin/ streptomycin $(100 \mathrm{U} / \mathrm{ml})$ (all from Life Technologies) and $2.5 \mathrm{mg} / \mathrm{ml}$ glucose (Sigma Aldrich) for $3-5$ days at $37^{\circ} \mathrm{C}$ in a humidified atmosphere with $5 \% \mathrm{CO}_{2}$, and then demyelinated with lysolecithin $(0.5 \mathrm{mg} / \mathrm{ml}, 16 \mathrm{~h})$. After incubation the lysolecithin containing medium was removed and replaced with fresh medium. At this point OSCs were used for all experiments. In some experiments OSCs were treated with $100 \mathrm{U} / \mathrm{ml}$ mouse $\operatorname{rIFN} \beta$ as indicated. For the usage of PLP-EGFP slices, fluorescent images were taken on indicated time points with an Olympus BX51 microscope at low magnification and in sterile conditions.

\section{Histology}

Brain and spinal cord were fixed with periodate-lysineparaformaldehyde (PLP) overnight, incubated in 10\% sucrose followed by $20 \%$ and $30 \%$ sucrose incubation steps. Organs were frozen in TissueTek (Sakura). Endogenous peroxidase activity and biotin were blocked. The staining 
of YFP was performed with a polyclonal crossreacting anti-GFP antibody overnight with $0.1 \%$ Triton at $4{ }^{\circ} \mathrm{C}$. Fluorescence was enhanced with TSA Fluorescein (PerkinElmer) according to the manufacturer's instructions. Sections were mounted with DAPI containing Vectashield [26]. Imaging was performed on an epifluorescence microscope (Eclipse TE 2000, Nikon) with digital camera (CCD-1300, Vosskuehler) and overlaid using Adobe Photoshop.

For immunocytochemistry cryo sections were stained with luxol fast blue (solvent blue from Sigma Aldrich) for demyelination and nuclear fast red (Sigma Aldrich) for nuclei. Imaging was performed on a fluorescent microscope (Olympus BX51) with a digital camera (Olympus F-View II).

OSCs were washed two times in warm PBS, fixed 40 minutes in $4 \%$ paraformaldehyde (PFA) and permeabilized for $1 \mathrm{~h}$ with $1 \%(\mathrm{v} / \mathrm{v})$ Triton X-100 (Sigma Aldrich) in PBS [25]. OSCs were blocked for $2 \mathrm{~h}$ with $5 \%$ $(\mathrm{v} / \mathrm{v})$ horse serum (Sigma Aldrich) in $0.5 \%(\mathrm{v} / \mathrm{v})$ Triton $\mathrm{X}-100$ in PBS. Primary antibodies were diluted in $2.5 \%$ $(\mathrm{v} / \mathrm{v})$ horse serum, $0.25 \%(\mathrm{v} / \mathrm{v})$ Triton X-100 in PBS and incubated for two days at $4^{\circ} \mathrm{C}$. After three times washing for 15 minutes with $0.1 \%(\mathrm{v} / \mathrm{v})$ Triton X-100 in PBS the OSCs were incubated with fluorescent secondary antibodies, diluted in $2.5 \%(\mathrm{v} / \mathrm{v})$ horse serum, $0.25 \%(\mathrm{v} / \mathrm{v})$ Triton X-100 in PBS, overnight at $4^{\circ} \mathrm{C}$. OSCs were counterstained with Hoechst (Life Technology) and mounted on glass slides with Immuno Mount $\left(\mathrm{DABCO}^{\mathrm{m}}\right)$. Primary and secondary antibodies used are described above. Imaging was performed on a laser scanning confocal microscope (Zeiss Axiovert $200 \mathrm{M} / \mathrm{LSM}$ 510) with a digital camera (Zeiss Axiocam) and a fluorescent microscope (Olympus BX51) with a digital camera (Olympus F-View II). All images were overlaid and processed with Adobe Photoshop. For better visualization of transplanted BV-2 cells on OSCs the cells were circled using Adobe Photoshop software. For quantifying the MBP staining intensity images were analyzed by ImageJ software.

\section{Statistical analysis}

All values in the figures are shown as indicated (mean \pm SEM or mean \pm SD). Statistical significance was assessed using Student's $t$ test (" $p<0.05$; ${ }^{* * *} p<0.01$; $\left.{ }^{* * * *} p<0.001\right)$.

\section{Results}

IFN $\beta$ is produced primarily by microglia during the effector phase of EAE

To characterize the expression of IFN $\beta$ and a representative IFN-inducible gene (Isg56) in CNS autoimmunity over a long term period we immunized C57BL/6 N mice with $\mathrm{MOG}_{35-55}$ peptide (hereafter referred to as $\mathrm{MOG}$ ) and characterized gene expression for 70 days. In the induction phase when clinical symptoms were still absent a significant increase in IFN $\beta$ mRNA levels was observed in the spinal cord and the spleen. A similar increase in IFN $\beta$ message, however, was also detected in adjuvant only controls. In the CNS, IFN $\beta$ mRNA levels increased steadily immediately after MOG immunization and reached a plateau in the effector phase of EAE (around day 14) when clinical symptoms were most severe (Figure 1a, Additional file 1: Figure S1a and S1b). However, during remission of clinical symptoms IFN $\beta$ expression were maintained at high levels in the CNS. In the spleen, after a transient increase in the induction phase, IFN $\beta$ levels remained low throughout the course of disease (Figure 1a, Additional file 1: Figure S1a). Overall Isg56 expression levels paralleled IFN $\beta$ expression levels in the CNS. In the spleen, no significant induction of Isg56 expression could be observed indicating that the functional effects of IFN $\beta$ were mainly found in the CNS by its direct activation of CNS resident cells or of circulating cells infiltrating the CNS (Figure 1a). To determine the cellular source of IFN $\beta$ we sorted mononuclear cells isolated from the spinal cord of MOG-immunized C57BL/ $6 \mathrm{~N}$ mice at the peak phase of EAE according to CD45 and CD11b expression. The vast majority of IFN $\beta$ mRNA was found in the $\mathrm{CD} 45^{\text {int }} \mathrm{CD} 11 \mathrm{~b}^{+}$cell fraction comprising mainly microglia. Low levels of IFN $\beta$ mRNA were also detected in CD45 $5^{\text {high }} \mathrm{CD} 11 \mathrm{~b}^{+}$immigrating myeloid cells. In $\mathrm{CD} 45^{+} \mathrm{CD}_{11 \mathrm{~b}^{-}}$lymphocytes IFN $\beta$ expression remained near the detection limit (Figure 1b). A similar expression pattern of IFN $\beta$ mRNA was identified in mononuclear cell subsets from the brain of MOG-immunized mice, although at lower mRNA levels (Additional file 1: Figure S1c). To further analyze the intrinsic ability of microglia to produce IFN $\beta$, we cultured primary adult microglia from wildtype (WT) and IFN $\beta / Y F P$ knock-in reporter $\left(\right.$ IFN $\beta^{\text {mob/mob }}$ ) mice [17] and stimulated them with the pathogen associated molecular compounds poly (I:C), CpG2216, LPS and Pam3CSK4 (Additional file 2: Figure S2). From these tested stimuli only poly (I:C) induced significant IFN $\beta$ expression. Up to $10 \%$ of $\operatorname{IFN} \beta^{\mathrm{mob} / \mathrm{mob}}$ microglia exhibited IFN $\beta /$ YFP expression (Figure 1c, Additional file 2: Figure S2a). Quantitative RT-PCR analyses of FACS-sorted IFN $\beta$-producing primary adult microglia demonstrated only slightly increased MDA-5 and RIG-I mRNA levels when compared to IFN $\beta$ nonproducers indicating gene expression for intracellular nucleic acid sensing pathways in microglia in general (Figure 1f). Immunofluorescence analysis verified coexpression of the microglial marker Iba1 with TLR3 in IFN $\beta / \mathrm{YFP}^{+}$primary microglia cells generated from IFN $\beta^{\text {mob/mob }}$ mice further demonstrating microglia express pattern recognition receptors for poly (I:C) (Figure $1 \mathrm{~d}$ and e). We therefore used in vivo stimulation with poly (I:C) to initially characterize IFN $\beta$-producing cells in the CNS in response to a strong and local IFN $\beta$ inducing stimulus. For 


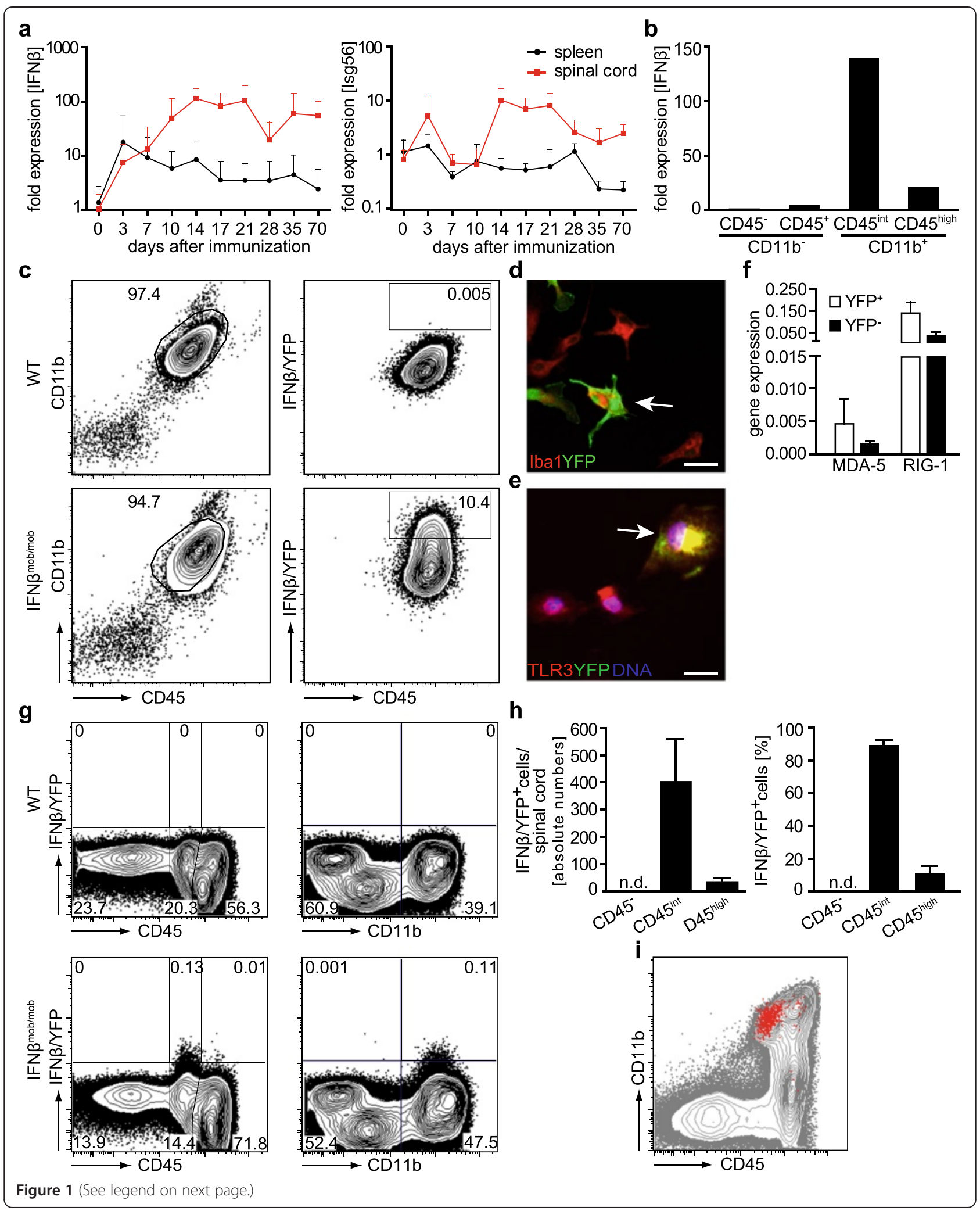


(See figure on previous page.)

Figure 1 IFN $\beta$ is predominantly produced by microglia during the effector phase of EAE. a EAE was induced in C57BL/6 N mice by immunization with $200 \mu \mathrm{g} \mathrm{MOG}_{35-55}$ peptide. Pertussis toxin was applied i.p. on d0 and d2. Spleen and spinal cord were isolated at indicated time points after immunization. Relative mRNA expression levels for IFN $\beta$ (left) and Isg56 (right) were determined by qRT-PCR. Data are pooled from two independent experiments. $n=6-7$. b On d17 after EAE induction mononuclear cells from the spinal cord of C57BL/6 N mice were sorted for CD45 and CD11b expression. Relative mRNA expression of IFN $\beta$ was determined by qRT-PCR in the indicated cell populations. $\mathbf{c}$ Primary adult microglia cultures were generated from WT and IFN $\beta^{\mathrm{mob} / \mathrm{mob}}$ mice and stimulated with poly (l:C) for $24 \mathrm{~h}$. IFNB/YFP expression was analyzed by flow cytometry. $\mathbf{d}$ and e Immunofluorescent stainings of primary adult microglia treated as in (c). Cells were stained with anti-lba1 (d) or anti-TLR3 (e) and for YFP for fluorescent microscopy. Scale bar represents $50 \mu \mathrm{m}$. f Primary adult microglia from IFN $\beta^{\text {mob/mob }}$ mice were stimulated as in (c) and sorted for $C D 45^{+}$CD $11 b^{+}$IFNB/YFP ${ }^{+}$vs. CD45 ${ }^{+}$CD $11 b^{+}$IFN $/$YFPP ${ }^{-}$expression. The relative mRNA expression of RIG-I and MDA-5 was determined by qRTPCR. $\mathbf{g}$ On d17 after immunization the phenotype of IFN $/$ YFP expressing cells from the spinal cord of WT and IFN $\beta^{\text {mob/mob }}$ mice was determined for CD45 and CD1 1b by flow cytometry. $\mathbf{h}$ Quantification of IFN $\beta /$ FPP $^{+}$cells isolated at d17 after immunization from the spinal cord of IFN $\beta^{\mathrm{mob} / \mathrm{mob}} \mathrm{mice}$. Shown is one representative experiment out of 3 independent experiments. $\mathbf{i}$ Representative dot blot shows an overlay of CD45 and CD1 $1 \mathrm{~b}$ expression of IFN $/$ YFP $^{+}$(red) and IFN $/$YFP $^{-}$(grey) cells in the spinal cord of IFN ${ }^{\mathrm{mob} / \mathrm{mob}}$ mice on d17 after immunization. Error bars represent SEM.

this, intrathecal stereotactic microinjection of poly (I:C) was performed on IFN $\beta^{\text {mob/mob }}$ mice. Here, CD $45^{\text {int }}$

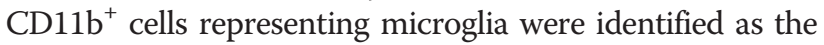
main producers of IFN $\beta / Y F P$ in the CNS by flow cytometry (Additional file 3: Figure S3a and S3b). In immunohistology IFN $\beta /$ YFP expressing cells showed a microglia-like morphology and localized in periventricular CNS regions (Additional file 3: Figure S3c). Next, we determined the identity of IFN $\beta /$ YFP expressing cells in CNS autoimmunity. No significant differences were observed in the disease course of IFN $\beta^{\mathrm{mob} / \mathrm{mob}}$ vs. WT mice (data not shown). Flow cytometric analysis of mononuclear cells isolated from the spinal cord and brain of IFN $\beta^{\text {mob/mob }}$ mice at the peak of disease (17 days after MOG-immunization) showed intermediate CD45 and high CD11b expression on more than $80 \%$ of IFN $\beta / \mathrm{YFP}^{+}$cells (Figure $1 \mathrm{~g}-\mathrm{i}$, Additional file 4 : Figure $\mathrm{S} 4$ ). Thus, the majority of endogenous IFN $\beta$ producing cells in the CNS during EAE were classified as microglia. Quantitative analysis revealed that IFN $\beta / Y F P$ expression is restricted to a total of about 400 cells within the spinal cord and less than 50 cells within the brain of MOG-immunized mice (Figure 1h, Additional file 4: Figure S4c). No IFN $\beta / Y F P$ expression was detectable in mononuclear cells from the spinal cord of naïve IFN $\beta^{\mathrm{mob} / \mathrm{mob}}$ mice (Additional file 4: Figure S4d and $\mathrm{S} 4 \mathrm{e})$. These findings demonstrate that during the EAE effector phase IFN $\beta$ is expressed in the CNS primarily by a low frequent subpopulation of microglia.

\section{IFN $\beta / Y F P$ producing cells are located within active lesions in the CNS at the peak of disease}

To characterize the anatomical localization of IFN $\beta$ producing cells within the CNS during autoimmunity we performed histological analyses of the spinal cord of IFN $\beta^{\mathrm{mob} / \mathrm{mob}}$ mice 17 days after MOG immunization. At this time point, active lesions could be observed within the grey but more prominently within the white matter of the spinal cord (Figure 2a). Nuclear fast red-positive
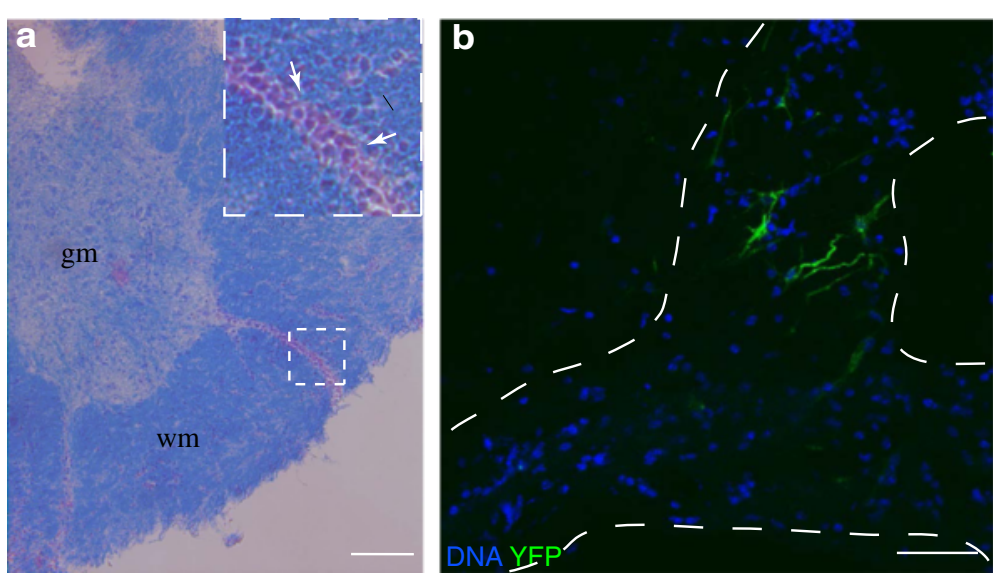

Figure 2 IFN $\beta$ /YFP producing cells localize to active lesions in the CNS at the peak of disease. a On day 17 after EAE induction spinal cord was isolated from IFN $\beta^{\mathrm{mob} / \mathrm{mob}}$ mice. Histological analysis of lesions in the spinal cord of IFN $\mathrm{R}^{\mathrm{mob} / \mathrm{mob}}$ mice at peak disease. Spinal cord sections were stained with luxol fast blue for the detection of demyelination and nuclear fast red for visualization of cellular infiltrates. Arrows indicate cellular infiltrates. gm: grey matter. wm: white matter. Scale bar represents $200 \mu \mathrm{m}$. b IFNß/YFP producing cells localize to lesions in the spinal cord of MOG-immunized IFN $\beta^{\text {mob/mob }}$ mice at d17. IFN $/$ YFP $^{+}$cells were stained with a YFP-crossreacting anti-GFP antibody. Dashed lines mark the area of cell infiltrates indicating lesions. Scale bar represents $50 \mu \mathrm{m}$. 
cell infiltrates were identified within demyelinated CNS sites as determined by luxol fast blue staining (Figure 2a). To identify IFN $\beta$ producing cells in situ spinal cord sections of IFN $\beta^{\mathrm{mob} / \mathrm{mob}}$ mice were stained for YFP and analyzed by confocal microscopy. IFN $\beta / Y F P$ signals in cellular bodies and their processes were predominantly detected in spinal cord areas containing high numbers of infiltrating cells underscoring that IFN $\beta$-producing cells accumulate in active lesions of the CNS during EAE (Figure 2b).

\section{Microglia but not astrocytes or neurons are the source of IFN $\beta$ production in situ}

Next, we determined whether non-hematopoietic CNS cells, not detectable in the flow cytometric analyses, contribute to IFN $\beta$ production during the inflammatory demyelinating response of the CNS. For this, histological analyses of cerebellar organotypic slice cultures (OSCs) harvested from 10 days old IFN $\beta^{\mathrm{mob} / \mathrm{mob}}$ mice were performed. OSCs were stimulated with poly (I:C) to induce IFN $\beta$ production and stained for the microglia marker Iba1, the astrocyte marker glial fibrillary acidic protein (GFAP) and the neuronal marker neurofilamentmedium (NF-M). IFN $\beta / Y F P$ immunoreactivity co-localized exclusively with Iba1 but not with GFAP or NF-M indicating that primarily microglia expressed IFN $\beta$ during immune activation in situ (Figure 3a-c). IFN $\beta / Y F P$ positive cells further co-expressed the phagocytic marker CD68 (Figure 3d) and the microglia activation marker Mac3 (Figure 3e) as well as the pattern recognition receptor TLR3 (Figure 3f). Histological analysis of spinal cord lesions from EAE-induced IFN $\beta^{\text {mob/mob }}$ mice at peak of disease revealed that only a small subset of IFN $\beta / \mathrm{YFP}^{+}$cells co-stained positive for CCR2, while the majority of IFN $\beta$-expressing cells was negative for this macrophage/myeloid marker (Figure 3g). Finally, underscoring their capacity to directly respond to TLR3
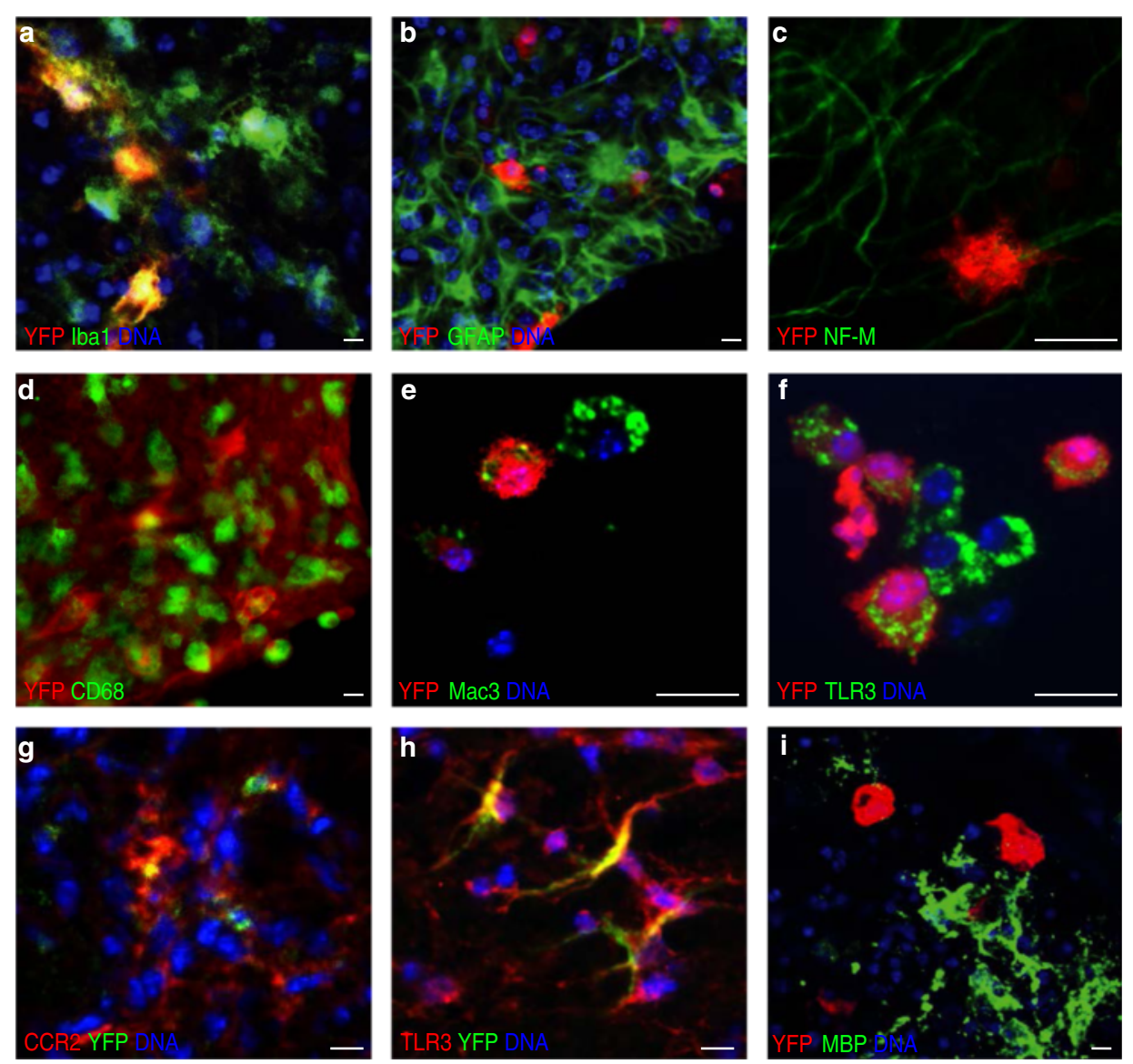

Figure $\mathbf{3}$ Microglia but not astrocytes or neurons are the primary source of IFN $\beta$ production in situ. a-f Immunofluorescent analysis of organotypic cerebellar slice cultures (OSCs) for co-expression of IFNB/YFP and different cell markers. OSCs were prepared as described in the methods and stimulated with $50 \mathrm{\mu g} / \mathrm{ml}$ poly (l:C) for $24 \mathrm{~h}$. OSCs were stained for Iba1 (a), GFAP (b), NF-M (c), CD68 (d), Mac3 (e) and TLR3 (f) together with IFNB/YFP. Scale bars represent $25 \mu \mathrm{m}$. $\mathbf{g}$ and $\mathbf{h}$ EAE was induced by immunization with $200 \mu \mathrm{g} \mathrm{MOG} 35-55$ peptide in IFN $\beta^{\text {mob/mob }}$ mice. Animals with a clinical score $>2$ were sacrificed at d17 and processed for histological analysis. Shown are representative spinal cord lesions stained for CCR2 (g) and TLR3 (h). Scale bars represent $25 \mu \mathrm{m}$. i Immunofluorescent analysis shows IFNß/YFP-expressing microglia in close association with myelin debris enriched areas in OSCs. OSCs were prepared and stimulated as described above and stained for MBP and IFNß/YFP. Scale bar represents $25 \mu \mathrm{m}$. 
ligands most IFN $\beta /$ YFP expressing cells were found positive for TLR3 (Figure 3h). Using confocal microscopy we found that IFN $\beta / \mathrm{YFP}^{+}$cells aggregated in close proximity to areas with a high content of myelin debris caused by spontaneous demyelination due to mechanical stress during cerebellar slice preparation (Figure 3i). These results point towards a possible functional role of IFN $\beta / Y F P$ producing cells within demyelinated sites in the CNS.

\section{IFN $\beta$ enhances microglia association with myelin debris and their phagocytic activity}

Phagocytosis by microglia is a cellular process to clear myelin debris in CNS autoimmunity [27]. To investigate whether IFN $\beta$ affected microglia association with myelin debris and phagocytotic capacity we utilized an ex vivo transplantation approach of IFN $\beta$ treated microglia onto demyelinated OSCs. To this aim microglia were treated with recombinant IFN $\beta$ (rIFN $\beta$ ), CMTMR labeled and co-transferred together with untreated DiD labeled cells at a 1:1 ratio onto demyelinated OSCs prepared from PLPEGFP mice $[20,28]$. Thus, migration of IFN $\beta$-stimulated versus untreated control microglia could be monitored on a single viable OSC together with GFP-tagged myelin debris structures. Demyelination occurred broadly on the OSC after the lysophosphatidylcholin (LPC) treatment, without harming the neuronal structures (Additional file 5: Figure S5a). Quantification of microglial cells that localized within myelin debris containing areas $1 \mathrm{~h}$ and $4 \mathrm{~h}$ after transplantation revealed a significantly increased accumulation of IFN $\beta$ treated microglia at these sites (Figure 4a). This specific migratory pattern was also observed in BV2 microglia cells upon treatment with IFN $\beta$ (Additional file 5: Figure $\mathrm{S} 5 \mathrm{~b}$ and S5c). These data indicate that IFN $\beta$ promotes the localization of microglia to demyelinated CNS sites.

Next, we examined whether IFN $\beta$ activates the phagocytic machinery in microglia cells. For this, expression of surface receptors and intracellular proteins involved in phagocytosis and phagosome maturation were assessed in WT, IFN $\beta^{-/-}$or IFNAR1 $1^{-/-}$primary microglia as well as the microglia derived, immortalized cell line BV2. Multiple phagocytosis associated genes were markedly upregulated in WT microglia in response to IFN $\beta$ (Figure 4b, Additional file 5: Figure S5d and S5e), among those, the sensor molecules complement receptor 3 (CR3), signal-regulatory protein alpha (SIRP $\alpha$ ) and Fc gamma Receptor 3 (FcyR3), shown to be directly involved in myelin phagocytosis in microglia and macrophages $[29,30]$. In addition, IFN $\beta$ upregulated microglial expression of molecules functionally involved in the general phagocytic machinery like macrophage scavenger receptor 1 (MSR1), CD68 and milk fat globule-EGF factor 8 (MfgE8) [31,32]. Furthermore, lysosome-associated membrane protein (LAMP) 1 and LAMP2 expression, both important for phagosome assembly were enhanced in response to IFN $\beta$ [33]. MBP positive vesicular structures could be observed within IFN $\beta$-activated, LAMP2 $^{+}$primary microglia indicating active phagocytosis (Additional file 5: Figure $\mathrm{S} 5 \mathrm{f}$ ). The fact that most phagocytosis associated genes and Isg56 were also upregulated in IFN $\beta^{-1-}$ microglia indicated a limited contribution of endogenously produced IFN $\beta$ to this gene activation (Figure $4 \mathrm{~b}$, Additional file 5: Figure S5d and S5g). We also verified the induction of Isg56 gene expression in WT and IFN $\beta^{-1-}$ microglia (Additional file 5: Figure S5g). None of these genes were found to be upregulated in IFNAR $1^{-1-}$ microglia verifying the specific effect of IFN $\beta$ (Figure $4 \mathrm{~b}$ ).

We further studied whether IFN $\beta$ affected the capacity of microglia to specifically phagocytose myelin debris. For this microglia cultures from adult WT, IFN $\beta^{-/-}$or IFNAR $^{-1-}$ mice and BV2 cells were treated with recombinant IFN $\beta$ (rIFN $\beta$ ) or left untreated and incubated with DII-fluorescent labeled myelin debris for measurement of phagocytosis efficiency by flow cytometry. WT and IFN $\beta^{-1-}$ microglia as well as BV2 microglia phagocytosed myelin debris more efficiently following treatment with IFN $\beta$ (Figure 4c and d, Additional file 5: Figure S5h and S5i). In contrast, IFNAR1 ${ }^{-1-}$ microglia did not exhibit increased phagocytotic rates of myelin debris (Figure 4c and $d)$. These data indicate that IFN $\beta$ and IFNAR1mediated signaling is required to stimulate microglial phagocytosis of myelin debris.

To investigate whether IFN $\beta$ would also induce phagocytosis in the ex vivo cerebellar slice culture model we used the PLP-EGFP reporter mouse model to monitor the clearance of myelin debris in situ [20]. Thus, we induced demyelination in OSCs from PLP-GFP mice with LPC and treated these cultures with rIFN $\beta$ (Figure 4e). By using PLP-EGFP OSCs it was possible to measure the myelin content in the same living slice culture before and after the treatment. The myelin debris content was significantly decreased by rIFN $\beta$ as visualized by reduced EGFP-PLP signal in slices after $24 \mathrm{~h}$ treatment as compared to the PBS-treated demyelinated control cultures (Figure $4 \mathrm{f}$ and $\mathrm{g}$ ). To verify the IFN $\beta$ specific effects in this model we prepared OSCs from WT, IFN $\beta^{-/-}$and IFNAR $^{-/-}$mice, induced demyelination with LPC and stimulated them with rIFN $\beta$ (Figure 4e). The myelin debris pattern was scored using an earlier established method (Additional file 6: Figure S6) [34]. This revealed that WT and IFN $\beta^{-1-}$ slice cultures stimulated by $\operatorname{rIFN} \beta$ showed significantly less myelin debris than untreated OSCs (Figure $4 \mathrm{~h}$ and i). IFNAR1 ${ }^{-/-}$OSCs exhibited no increase in the removal of myelin debris in response to rIFN $\beta$, providing additional evidence that IFN $\beta$ dependent mechanisms drive myelin debris removal. In a complementary approach we investigated whether endogenously produced IFN $\beta$ also affects removal of myelin debris in the CNS. Here OSCs from WT and 


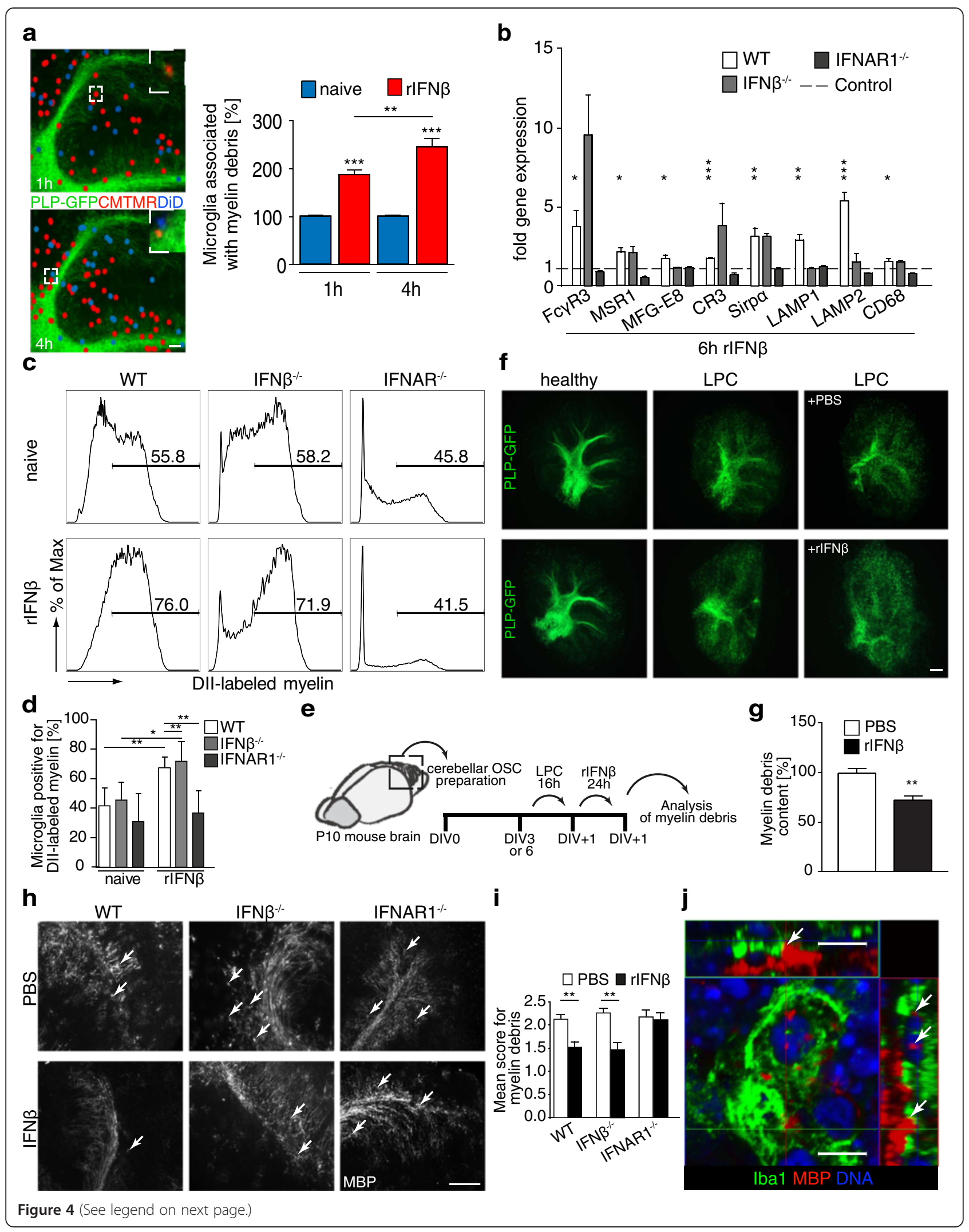




\begin{abstract}
(See figure on previous page.)
Figure 4 IFN $\beta$ enhances microglia association with myelin debris and phagocytotic activity. a Co-cultures of sorted primary adult microglia with demyelinated OSCs. Microglia from C57BL/6 N mice treated with rIFN 3 and labeled with CMTMR (red) and untreated DiD-labeled (blue) microglia were mixed 1:1 and co-transferred onto LPC-demyelinated OSCs $(n=16)$ from PLP-EGFP mice. For better visualization transplanted cells were marked using Adobe Photoshop software. Diagrams show percentages of rIFN $\beta$-treated (red) and control (blue) microglia associated with myelin debris. $\mathbf{b}$ Expression of phagocytosis associated genes in WT, IFN ${ }^{-/-}$and IFNAR1 ${ }^{-1-}$ primary adult microglia after stimulation with rIFN $\beta$ ( $6 \mathrm{~h}$ ). $\mathrm{n}=2-4$. $\mathbf{c}$ WT, IFN ${ }^{-/-}$and IFNAR1 ${ }^{-/-}$primary adult microglia were left untreated or stimulated with rIFN $\beta$ ( $24 \mathrm{~h}$ ). DII-labeled myelin was added for the last hour of stimulation. Uptake of myelin was quantified by flow cytometry. $\mathbf{d}$ Quantification of phagocytosis activity measured in (c) ( $\mathrm{n}=4-7$ ). e Experimental setup for analysis of myelin phagocytosis in OSCs (f,g). OSCs were LPC-demyelinated, treated with rIFN 3 or PBS (24 h), and analysed for myelin debris content. DIV, Days In Vitro. f OSCs from PLP-EGFP mice treated as in (e) were imaged. g PLP-EGFP-intensity was analyzed by ImageJ software. ( $n=16-22)$. $\mathbf{h}$ OSCs from WT, IFN ${ }^{-/-}$and IFNAR1 ${ }^{-/-}$mice, cultured for 3 days before LPC-demyelination were treated with rIFN $\beta$ (24 h) or left untreated and stained for MBP. i Quantification of myelin debris in OSCs from WT, IFN $\beta^{-1-}$ and IFNAR $1^{-1-}$ mice after rIFN $\beta$ treatment. Scoring as described in Additional file 6: Figure S6. $(n=3-4)$. j Confocal Z-stack image from a phagocytic microglia in an WT OSC after poly (I:C) treatment and demyelination. Arrows indicate internalized myelin. Error bars represent SEM (a,b,g,i) and SD (d). Scale bars represent $10 \mu \mathrm{m}(\mathbf{j}), 100$ Mm (a,h), 1 mm (f).
\end{abstract}

IFN $\beta^{-1-}$ mice were treated with poly (I:C) and subjected to LPC-induced demyelination. We found a significantly higher intensity of myelin debris in OSCs of IFN $\beta^{-/-}$compared to WT slices which further underscored that IFN $\beta$ is functionally involved in the clearance of myelin debris (Additional file 5: Figure S5j and S5k). Myelin debris was detected within the cytoplasm of $\mathrm{Iba}^{+}$microglia cells in LPC-treated OSCs by confocal microscopy (Figure 4j). This points to an uptake of myelin debris by microglia induced by IFN $\beta$.

\section{Myelin debris accumulation in the CNS is increased in EAE in the absence of IFN $\beta$ or its receptor}

According to our data, IFN $\beta$-producing cells are localized in active lesions of the inflamed CNS and phagocytic potential of primary adult microglia was enhanced after stimulation with rIFN $\beta$ in vitro. To assess the in vivo relevance of these findings, we analyzed brain sections and visualized myelin debris accumulation in MOG-EAE induced mice. The majority of lesion infiltrating cells were positive for CCR2 and Mac3 (Figure 5a). To identify the distribution of microglia in active cerebellar lesions and to investigate the myelin debris content we stained brain sections of $\mathrm{WT}, \mathrm{IFN} \mathrm{\beta}^{-/-}$or IFNAR $1^{-/-}$mice for Iba1 and MBP at peak disease (Figure 5b). As assessed by fluorescence microscopy activated microglia characterized by their amoeboid morphology were present in active lesions in close proximity with granular myelin debris. Enhanced amounts of granular myelin debris were found in lesions of $\mathrm{IFN} \mathrm{\beta}^{-/-}$and IFNAR $1^{-/-}$as compared to WT mice where myelin appears more evenly distributed. These results indicate that a lack of IFN $\beta$ production or the type I IFN signaling pathway leads to increased myelin debris amounts in active lesions of CNS tissue.

\section{IFN $\beta$-producing microglia act as orchestrators of myelin debris removal}

Our findings so far indicate that on the one hand microglia produce IFN $\beta$ in CNS autoimmunity while on the other hand IFN $\beta$ potently induces removal of myelin debris in OSCs as well as CNS lesions in the EAE model. Thus, we wanted to clarify whether microglia additional to their phagocytotic capacity are the relevant orchestrators of IFN $\beta$ mediated effects in myelin debris removal in vivo. In primary microglia cell cultures we observed that multiple cells positive for phosphorylated IRF7 localize in close proximity to single IFN $\beta$ producers in $\mathrm{Mac}^{+}$cell accumulations indicating promiscuous activation of IFNAR signalling in neighboring cells (Figure 6a). To investigate whether IFN $\beta$ producing microglia harbor the capacity to control clearance of myelin debris in the CNS we transplanted IFN $\beta$-producing or non-producing microglia onto cerebellar slice cultures (Figure 6b). To this end primary microglia cells from adult IFN $\beta^{\text {mob/mob }}$ mice were stimulated with poly (I:C) and FACS sorted into IFN $\beta / Y F P-$ producing versus IFN $\beta / Y F P$ non-producing cells. The separated microglia populations were labeled with DiD and transplanted onto LPC-demyelinated OSCs isolated from WT, IFN $\beta^{-/-}$or IFNAR $1^{-/-}$mice. DiD transplanted microglia could be visualized embedded within the population of resident microglia of the OSCs (Figure 6c). To quantify myelin debris surrounding transplanted microglia in demyelinated areas histological staining for MBP was performed. As shown in a representative image of slice co-cultures, IFN $\beta / \mathrm{YFP}^{+}$microglia integrated in demyelinated regions and associated with affected myelin structures (Figure 6d). Quantitative analysis revealed a significantly decreased intensity of MBP debris in areas proximal to IFN $\beta / \mathrm{YFP}^{+}$microglia as compared to IFN $\beta / \mathrm{YFP}^{-}$microglia on WT or IFN $\beta^{-1-}$ slice cultures (Figure 6e). In contrast, no difference in MBP intensity was measurable between areas proximal to IFN $\beta / \mathrm{YFP}^{+}$ vs. IFN $\beta / \mathrm{YFP}^{-}$microglia transplanted onto IFNAR1 ${ }^{-/-}$ slice cultures. Thus IFN $\beta$-expressing microglia can act as inducer cells for clearance of myelin debris. This process is mediated via type I IFN receptor signalling. Taken together, these data demonstrate that IFN $\beta$ producing microglia exhibit an enhanced capacity to induce phagocytosis of myelin debris highlighting their 

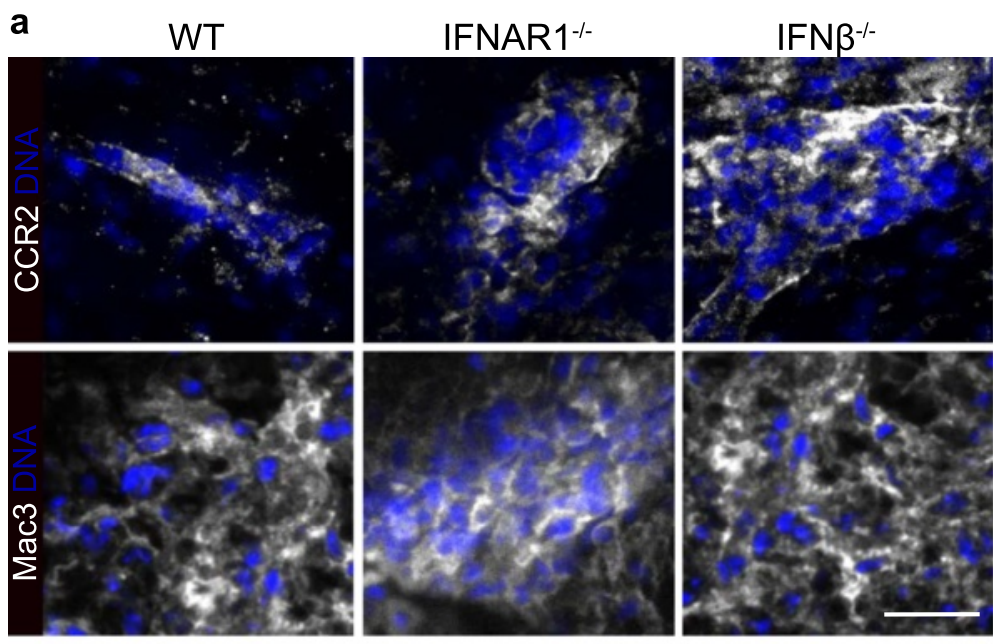

b

IFNAR $1^{-1-}$
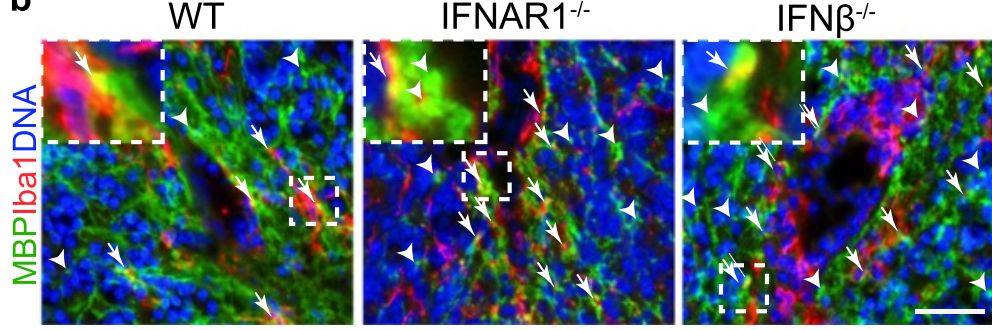

Figure 5 Myelin debris accumulation in the CNS is increased in EAE in the absence of IFN $\beta$ or its receptor. EAE was induced by immunization with $200 \mu \mathrm{g} \mathrm{MOG}_{35-55}$ peptide in WT, IFNB ${ }^{-/-}$and IFNAR1 ${ }^{-/}$mice. Animals of each genotype with an equivalent clinical score $(>2)$ were sacrificed at d17. Shown are representative brain sections stained for CCR2 and Mac3 (a) and Iba1 and MBP (b) together with DAPI using fluorescence microscopy. Arrows mark accumulated myelin debris in close proximity to activated microglia and arrow heads mark myelin debris in the lesion structure. Scale bar represents $25 \mu \mathrm{m}$ (a) and $50 \mu \mathrm{m}$ (b).

functional role as relevant orchestrators for clearance of myelin debris in the CNS.

\section{Discussion}

The high relevance of IFN $\beta$ in the therapy of MS and its pleiotropic protective effects in mice and men are irrevocable. Here we identified the so far ill-defined IFN $\beta$ producing cells in CNS autoimmunity as primarily microglia in active lesions within the CNS. We further demonstrate that these microglia orchestrate phagocytosis of myelin debris in a process mediated by and dependent on IFN $\beta$.

Our time course analyses showed that IFN $\beta$ production and the expression of the IFN-inducible Isg56 in the CNS starts with the onset of clinical symptoms and increases in parallel with the disease score of MOGinduced EAE. These findings extend previous data showing that IFN $\beta$ is produced at the peak of EAE exclusively in the CNS [3]. In peripheral lymphoid organs, however, we found IFN $\beta$ upregulated early after MOGimmunization and decreased afterwards. This initial expression of IFN $\beta$ is also observed when CFA is administered in the absence of MOG and is therefore the result of the immuno-adjuvant containing heat-inactivated $M$. tuberculosis that induces a strong innate immune response. Plasmacytoid dendritic cells have been shown to be responsible for this early produced IFN $\beta$ [35] that exacerbates the clinical course of EAE presumably via contributing to the priming of encephalitogenic $\mathrm{T}$ cells. Expression of IFN $\alpha / \beta$ in the effector phase of disease instead was suggested to mediate protective effects by acting directly on myeloid cells [3].

We identified microglia, but not astrocytes or neurons as the major cellular source of IFN $\beta$ in the CNS at peak EAE. The identity of IFN $\beta$ producing cells in the course of EAE has been a long-standing topic of debate. In general, different cell types, mainly professional antigen presenting cells, are capable of producing IFN $\beta$ in the context of immune activation. Plasmacytoid and classical dendritic cells are capable of IFN $\beta$ production after TLR9and TLR3/MDA5-stimulation, respectively $[17,36]$. During viral infections in the CNS also neurons have been shown to produce IFN $\beta$ [37]. In vitro murine neurons as well as microglia produced IFN $\beta$ after poly (I:C) stimulation $[38,39]$. Other brain resident cells reported to produce 


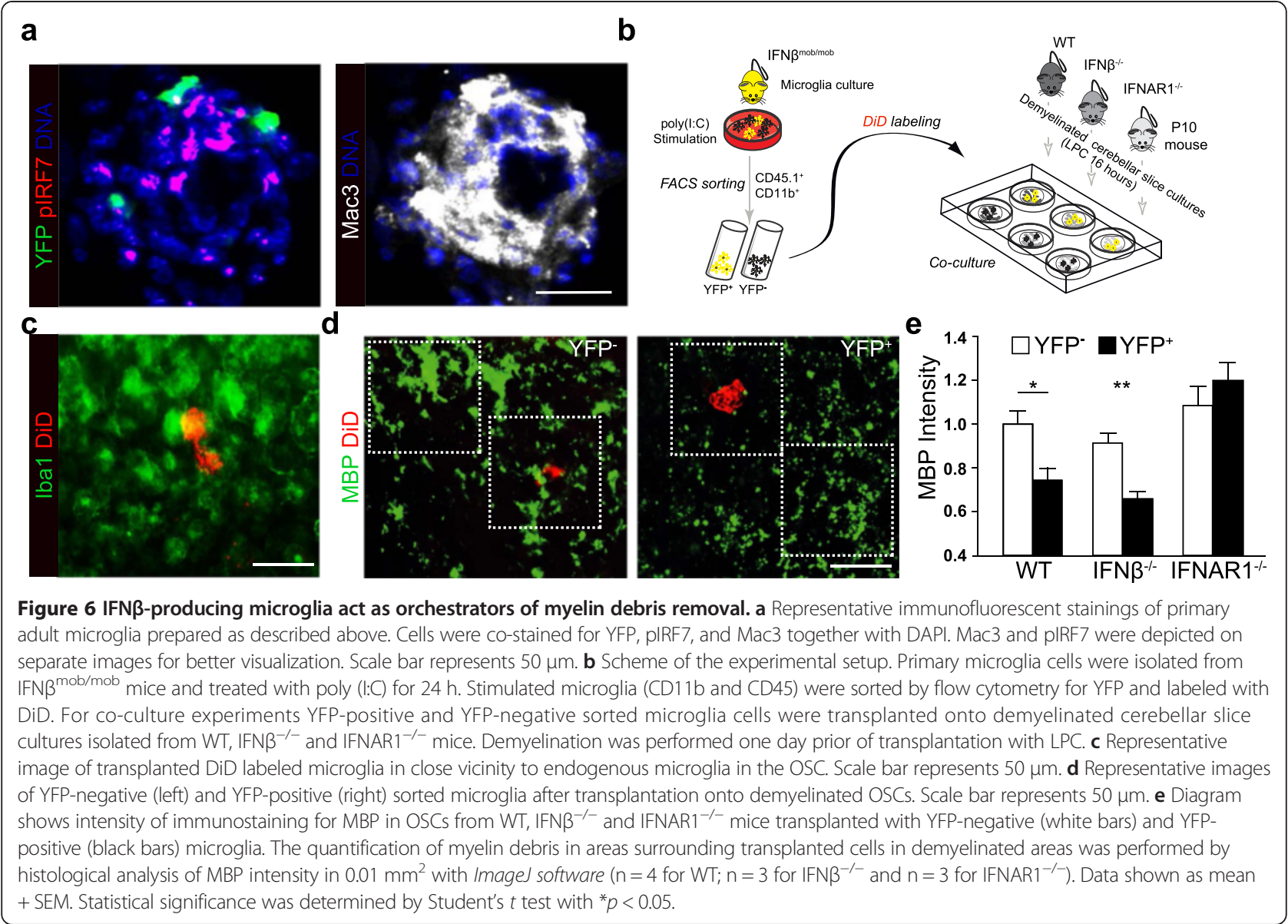

predominantly IFN $\alpha$ are astrocytes as shown in AicardiGoutières Syndrome, a rare neurodevelopmental disorder [40]. In MS IFN $\beta$ production was detected in active lesions in cells defined as macrophages and astrocytes based on their morphology [41]. Also, based on morphological studies it was suggested earlier that IFN $\beta$ may be produced by ramified microglia or infiltrating cells in EAE [4]. Our study defines activated microglia as the prominent IFN $\beta$-producing cell type in the CNS as characterized by an intermediate CD45 and high Iba1 expression as well as a hypermorphic-rounded morphology in the IFN $\beta / Y F P$ fluorescence reporter mouse model [42-44]. It has been suggested that an activated CD45 ${ }^{\text {high }} \mathrm{CD} 11 \mathrm{~b}^{+}$microglia subset with the capacity to differentiate into macrophages or dendritic-like cells plays an active role in the pathogenesis of EAE $[21,45]$. However, our data indicate that IFN $\beta$ expressing microglia did not acquire a $\mathrm{CD} 45^{\text {high }} \mathrm{CD} 11 \mathrm{~b}^{+}$ phenotype during MOG-EAE excluding that they phenotypically and functionally resemble the earlier described subset. The fact that in our study IFN $\beta$ production was identified in microglia not only during EAE but also after intrathecal injection of the molecular pathogen compound poly (I:C) points to a specialized function of these CNS resident phagocytes to produce type I IFNs. Of note, at early timepoints after intrathecal poly (I:C) application Khorooshi et al. describe a quick mobilization of IFN $\beta$ producing myeloid cells from the periphery into the CNS (personal communication). The discrepancies between these two studies could be explained by the different modes intrathecal poly (I:C) application was used (intracerebroventricular vs. intracisterna magna), that may cause induction of divergent chemokine patterns driving leukocyte infiltration. However, in this report, also microglia were shown to contribute to IFN $\beta$ production. The IFN $\beta$ expression capacity by these cells is in line with our findings on IFN $\beta$ production by microglia in CNS autoimmunity without prior poly (I:C) stimulation. We could show that IFN $\beta$-producing microglia localized in the proximity of myelin lesions and exhibit a superior capacity to induce phagocytosis of myelin debris in surrounding cells. It is yet unclear which chemotactic factors guide positioning of microglia into areas of demyelination in CNS autoimmunity. It has been suggested that astrocytes direct migration and activation of microglia and macrophages in demyelinating lesions via expression of CCL2 and CXCL10. Correspondingly microglia and immigrating 
macrophages in MS lesions stained positive for CXCR3 and CCR2 in MS lesions [46]. Recent elegant data defined CCR2 as a selective marker for infiltrating macrophages in the inflamed CNS [47-49]. Our data do not rule out that immigrating myeloid cells contribute to IFN $\beta$ production as indicated by (i) detection of IFN $\beta$ mRNA in peripheral tissues early after immunization, (ii) CCR2 expression in a subset of IFN $\beta / \mathrm{YFP}^{+}$cells in CNS lesions, and (iii) direct flow cytometric detection of CD45 ${ }^{\text {high }}$ IFN $\beta$ / YFP $^{+}$cells.

The most important finding of our study is that strategically positioned IFN $\beta$ producing microglia within active CNS lesions exhibit a superior capacity to induce myelin debris removal in surrounding tissue phagocytes. Effective clearance of myelin debris is a critical step in the pathogenesis of MS as well as EAE. While microglia have been attributed important roles in the inflammatory response during infections and CNS autoimmunity [50] it is still a matter of debate whether microglia represent efficient phagocytes in the CNS [27]. Here we could show that phagocytosis of myelin debris by microglia was dependent on IFN $\beta$ and its receptor IFNAR1. These findings are supported by recent studies showing that in vitro microglia deficient in TIR domain containing adapter inducing interferon beta (TRIF) ${ }^{-1-}$ less effectively cleared axonal debris. These microglia further exhibited an increased threshold for activation of interferon-regulated genes, suggesting that IFN $\beta$ may upregulate phagocytic activity [51]. In contrast to this, earlier studies suggested that IFN $\beta$ suppresses the phagocytosis of myelin debris in vitro [3]. In these studies, phagocytic activity, however, was tested in peritoneal macrophages or $\mathrm{CD}_{11} \mathrm{~b}^{+}$cells in the CNS not differentiating between resident microglia and immigrated macrophages from the periphery. The discrepancy to our data can therefore be explained by differences in the phagocytic activity of microglia and macrophages [52].

The EAE in vivo model exhibits a high variability in disease severity and in the localization of CNS lesions between individual animals. Also the suppressive effect of IFN $\beta$ and IFNAR mediated signalling on EAE development might reduce demyelination as well as microglia activation $[3,4]$, and Khorooshi et al., personal communication. To eliminate this variability, the unwanted bias and the influence of peripheral immune responses, we used the model of LPC-induced demyelination on OSCs [28] allowing a reproducible and controlled evaluation of IFN $\beta$ and microglia mediated effects. IFN $\beta$ expressing microglia specifically localized to demyelinated regions in OSCs and further showed lower amounts of myelin debris in their direct proximity in comparison to IFN $\beta$ nonproducers indicative of a more efficient myelin debris removal. This phagocytosis activating effect was confirmed by transfer of IFN $\beta /$ YFP producing microglia on demyelinated WT as well as IFN $\beta^{-/-}$OSCs but was not observed on IFNAR1 deficient OSCs. These data point towards a pivotal function of IFN $\beta$ producing microglia in the orchestration of phagocytosis of myelin debris by not only neighboring microglia but also immigrating phagocytes in CNS autoimmunity. It remains to be shown, however, whether the effects observed in EAE can be translated into human MS. While myelin phagocytosis has been suggested to contribute to damage processes in MS by the associated oxidative burst, a number of studies have shown beneficial effects for the effective clearing of myelin debris [27]. Phagocytosis of myelin debris by activated microglia was observed in MS lesions [53] and was essential to promote regeneration [54]. Recently, overexpression of the phagocytosis triggering receptor TREM2 was shown to reduce the severity of clinical symptoms in EAE [55]. Myelin debris was shown to impair remyelination by inhibiting differentiation as well as the recruitment of oligodendrocyte precursor cells after injury [56]. Also, myelin directly inhibited axonal re-growth as it contains several growth inhibitory molecules such as Nogo A [57]. A secondary protective effect of IFN $\beta$-activated myelin phagocytosis might be the induction of a regulatory type of microglia resembling M2 macrophages [58].

\section{Conclusions}

A number of studies indicate that myelin clearance in the CNS after demyelination is protective or ameliorates disease symptoms in EAE and MS. Here, we identify microglia as orchestrators of myelin phagocytosis via production of the protective IFN $\beta$ at the peak of CNS autoimmunity. Our findings represent novel insights into the in vivo functions of microglia-derived IFN $\beta$ and the feasibility of novel therapeutic approaches for MS specifically targeting CNS microglia.

\section{Additional files}

\footnotetext{
Additional file 1: Figure S1. Clinical score of C57BL/6 N mice after MOG immunization and IFN $\beta$ expression in the CNS. a EAE was induced in C57BL/6 N mice by immunization with MOG $_{35-55}(200 \mu \mathrm{g})$. Pertussis toxin was applied i.p. on d0 and d2. Data represent 6 - 15 animals for each time point. Error bars represent SEM. b C57BL/6 N mice were treated with CFA only. Pertussis toxin was applied i.p. on $\mathrm{d} 0$ and $\mathrm{d} 2$. The spleen and the spinal cord were isolated at indicated time points after CFA immunization. Relative mRNA expression levels of IFN $\beta$ were determined by qRT-PCR. Error bars represent SD. $n=3-4$. c IFN $\beta$ expression on $d 17$ after MOG-immunization. Shown is IFN $\beta$ mRNA expression of sorted cell populations isolated from the brain of $\mathrm{C} 57 \mathrm{BL} / 6 \mathrm{~N}$ mice according to their CD45 and CD11b expression. The relative mRNA expression of IFN $\beta$ was determined by qRT-PCR.

Additional file 2: Figure S2. Induction of IFN $\beta$ production in primary adult microglia by molecular pathogen compounds. a and b Primary adult microglia cultures were generated from WT and IFN $\beta^{\mathrm{mob} / \mathrm{mob}}$ mice. On d14 microglial cells were stimulated with $50 \mu \mathrm{g} / \mathrm{ml}$ poly (l:C), $6 \mu \mathrm{g} / \mathrm{ml}$
} 
CpG2216, $100 \mathrm{ng} / \mathrm{ml}$ LPS or $1 \mathrm{\mu g} / \mathrm{ml}$ Pam3CSK4 for $24 \mathrm{~h}$. IFNß/YFP (a) and CD86 (b) expression was analyzed by flow cytometry.

Additional file 3: Figure S3. IFN $\beta$ expression in the CNS after intrathecal poly (I:C) stimulation. WT and IFN $\beta^{\mathrm{mob} / \mathrm{mob}}$ mice were injected intrathecally with $6 \mu \mathrm{g}$ poly (I:C). a IFN $\beta / Y F P$ expression in the brain-isolated mononuclear cells was determined by flow cytometry $24 \mathrm{~h}$ after stimulation. DAPI ${ }^{-}$cells were gated for CD45, CD $11 \mathrm{~b}$ and IFNB/YFP expression. $b$ Representative dot blot shows an overlay of CD45 and CD11b expression of IFN $/$ FFP $^{+}$(red) and IFN $/$FFP $^{-}$(grey) cells isolated from the brain of IFN $\beta^{\text {mob/mob }}$ mice on $d 17$ after immunization. c Localization of IFN $\beta / Y F P$ expressing cells was determined by immunofluorescence of brain slices of IFN $\beta^{\mathrm{mob} / \mathrm{mob}}$ mice. IFN $\beta /$ YFP was stained with a YFP-crossreacting anti-GFP antibody. Nuclei were stained with DAPI (grey) (10-fold magnification).

Additional file 4: Figure S4. Microglia express IFN $\beta / Y F P$ in MOG-EAE in the brain. a EAE was induced in WT and IFN $\beta^{\text {mob/mob }}$ mice with $200 \mu \mathrm{g}$ $M \mathrm{MG}_{35-55}$ peptide. On d17 after immunization the phenotype of IFN/NFP expressing cells from the brain was determined in $\mathrm{DAPI}^{-}$cells stained for CD45 and CD11b by flow cytometry. b Representative dot blot shows an overlay of CD45 and CD11b expression of IFNB/YFP' (red) and IFNB/YFP' (grey) cells isolated from the brain of IFN $\mathrm{m}^{\mathrm{mob} / \mathrm{mob}}$ mice on d17 after immunization. c Quantification of IFNB/YFP ${ }^{+}$cells in the brain of IFN $\beta^{\text {mob/mob }}$ mice on 117 after immunization. Error bars represent SEM. d Mononuclear cells from the spinal cord of naiive WT and IFN $\beta^{\text {mob/mob }}$ mice were analyzed by flow cytometry as shown in a. e Representative dot blot of an overlay of CD45 and CD11b expression shows no IFNB/YFP expressing cells under naïve conditions.

Additional file 5: Figure S5. Impact of IFN $\beta$ on myelin phagocytosis. a Histological analysis of LPC-demyelinated or untreated OSCs stainied with anti-NF-M and anti-MBP antibodies. b Untreated microglia were labeled with DiD (blue circles) and mixed (ratio 1:1) with CFSE labeled cells treated with rIFN $\beta$ for $24 \mathrm{~h}$ (red circles) before transfer onto LPC-demyelinated OSCs. For better visualization transplanted BV2 cells were marked using Adobe Photoshop software. c Quantification of myelin associated BV2 cells from (b). Diagram shows percentages of IFN $\beta$-treated (red bars) and control (blue bars) BV2 cells associated with myelin debris. $(n=4)$. $d$ qRT-PCR for genes involved in the phagocytic process in WT, IFN $\beta^{-1-}$ and IFNARI ${ }^{-1-}$ primary adult microglia stimulated with rIFN $\beta(24 h)$. $(n=2-4)$. e Expression of genes involved in the phagocytic process in BV2 microglia upon IFN $\beta$ treatment. Cells were stimulated as in (d). $(n=3)$. $f$ Immunofluorescent staining of primary adult microglia after incubation with DII-labeled myelin for $2 \mathrm{~h}$. Cells were stained with anti-lbal, anti-LAMP2 and anti-MBP antibodies for fluorescent microscopy. g qRT-PCR analysis of Isg56-gene expression in WT, IFN $\beta^{-/-}$and IFNAR ${ }^{-/-}$primary microglia treated with rIFNß $(6 h, 24$ h). $h$ and i Uptake of DII-labeled myelin by BV2 cells in response to rIFN $\beta$. BV2 cells were $24 \mathrm{~h}$ pre-treated with rIFN $\beta$ and incubated with DII-labeled myelin for $1 \mathrm{~h}$. h Quantification of BV2 cells co-localized with DII-myelin. $(n=6)$. i BV2 cells were stained for Iba1 and Hoechst. $j$ and $k$ Quantitative analysis of myelin debris in demyelinated OSCs of IFNB ${ }^{+/+}$and IFNB ${ }^{-/-}$mice. Demyelination was induced as in (a) and production of IFN $\beta$ induced with poly (I:C). On d6 MBP intensity was analyzed using ImageJ software. $(n=3)$. Error bars represent SEM. Scale bars represent $50 \mu \mathrm{m}(\mathrm{f}, \mathrm{i}), 100 \mu \mathrm{m}(\mathrm{a}, \mathrm{b}), 1 \mathrm{~mm}(\mathrm{j})$.

Additional file 6: Figure S6. Scoring table for myelin debris quantification. OSCs were prepared as described and demyelinated by LPC treatment. OSCS were further processed for MBP-staining. The scoring scheme represents the amount of myelin debris in $0.1 \mathrm{~mm}^{2}$ in OSCs stained for MBP. A score of " 0 " points to no visible myelin debris and score " 3 " displays an area covered with myelin debris (indicated by arrows). Scale bar represents $100 \mu \mathrm{m}$.

\section{Competing interests}

The authors declare that they have no competing interests.

\section{Authors' contributions}

MK, RS, AP, JA, TP, OA, SS conceived and designed the experiments; MK, RS, $A P, S K, J B, J A, M G$, Jl performed the experiments; MK, RS, AP analyzed data; TP, OA, SS supervised the work; MK, RS, AP, JA, SS wrote the manuscript. All authors read and approved the final manuscript.
Authors' information

Magdalena Kocur, Reiner Schneider and Ann-Kathrin Pulm are co-first authors. Orhan Aktas and Stefanie Scheu are co-senior authors.

\section{Acknowledgments}

This work was supported by the Deutsche Forschungsgemeinschaft (SCHE692/3-1, SCHE692/4-1, EXC 1003-CiM) and the Strategic Research Fund of the Heinrich-Heine-University Duesseldorf. For some illustrations the servier medical art database was used.

\section{Author details}

${ }^{1}$ Institute of Medical Microbiology and Hospital Hygiene, Medical Faculty, University of Duesseldorf, Universitaetsstr. 1, 40225 Duesseldorf, Germany. ${ }^{2}$ Department of Neurology, Medical Faculty, University of Duesseldorf, Duesseldorf, Germany. ${ }^{3}$ Department of Psychiatry, University of Muenster, Muenster, Germany. ${ }^{4}$ Cluster of Excellence EXC 1003, Cells in Motion, Muenster, Germany.

Received: 30 January 2015 Accepted: 3 February 2015

Published online: 03 April 2015

\section{References}

1. Aktas O, Kieseier B, Hartung HP (2010) Neuroprotection, regeneration and immunomodulation: broadening the therapeutic repertoire in multiple sclerosis. Trends Neurosci 33:140-152, doi:10.1016/j.tins.2009.12.002

2. Paty DW, Li DK (1993) Interferon beta-1b is effective in relapsing-remitting multiple sclerosis. II. MRI analysis results of a multicenter, randomized, double-blind, placebo-controlled trial. UBC MS/MRI Study Group and the IFNB Multiple Sclerosis Study Group. Neurology 43:662-667

3. Prinz M, Schmidt H, Mildner A, Knobeloch KP, Hanisch UK, Raasch J, Merkler D, Detje C, Gutcher I, Mages J, Lang R, Martin R, Gold R, Becher B, Bruck W, Kalinke U (2008) Distinct and nonredundant in vivo functions of IFNAR on myeloid cells limit autoimmunity in the central nervous system. Immunity 28:675-686, doi:10.1016/j.immuni.2008.03.011

4. Teige I, Treschow A, Teige A, Mattsson R, Navikas V, Leanderson T, Holmdahl $R$, Issazadeh-Navikas S (2003) IFN-beta gene deletion leads to augmented and chronic demyelinating experimental autoimmune encephalomyelitis. J Immunol 170:4776-4784

5. Hohlfeld R, Wekerle H (2001) Immunological update on multiple sclerosis. Curr Opin Neurol 14:299-304

6. Touil T, Fitzgerald D, Zhang GX, Rostami A, Gran B (2006) Cutting Edge: TLR3 stimulation suppresses experimental autoimmune encephalomyelitis by inducing endogenous IFN-beta. J Immunol 177:7505-7509

7. Calabresi PA, Pelfrey CM, Tranquill LR, Maloni H, McFarland HF (1997) VLA-4 expression on peripheral blood lymphocytes is downregulated after treatment of multiple sclerosis with interferon beta. Neurology 49:1111-1116

8. Nelissen I, Ronsse I, Van Damme J, Opdenakker G (2002) Regulation of gelatinase B in human monocytic and endothelial cells by PECAM-1 ligation and its modulation by interferon-beta. J Leukoc Biol 71:89-98

9. Wiesemann E, Deb M, Trebst C, Hemmer B, Stangel M, Windhagen A (2008) Effects of interferon-beta on co-signaling molecules: upregulation of CD40, CD86 and PD-L2 on monocytes in relation to clinical response to interferonbeta treatment in patients with multiple sclerosis. Mult Scler 14:166-176, doi:10.1177/1352458507081342

10. Teige I, Liu Y, Issazadeh-Navikas S (2006) IFN-beta inhibits T cell activation capacity of central nervous system APCs. J Immunol 177:3542-3553

11. Pette M, Pette DF, Muraro PA, Farnon E, Martin R, McFarland HF (1997) Interferon-beta interferes with the proliferation but not with the cytokine secretion of myelin basic protein-specific, T-helper type 1 lymphocytes. Neurology 49:385-392

12. Gniadek $\mathrm{P}, \mathrm{Aktas} \mathrm{O}$, Wandinger KP, Bellmann-Strobl J, Wengert $\mathrm{O}$, Weber $\mathrm{A}$, von Wussow P, Obert HJ, Zipp F (2003) Systemic IFN-beta treatment induces apoptosis of peripheral immune cells in MS patients. J Neuroimmunol 137:187-196

13. Liu Y, Carlsson R, Comabella M, Wang J, Kosicki M, Carrion B, Hasan M, Wu X, Montalban X, Dziegiel MH, Sellebjerg F, Sorensen PS, Helin K, Issazadeh-Navikas $S$ (2014) FoxA1 directs the lineage and immunosuppressive properties of a novel regulatory T cell population in EAE and MS. Nat Med 20:272-282, doi:10.1038/nm.3485

14. Liu Y, Hao W, Letiembre M, Walter S, Kulanga M, Neumann H, Fassbender K (2006) Suppression of microglial inflammatory activity by myelin 
phagocytosis: role of p47-PHOX-mediated generation of reactive oxygen species. J Neurosci 26:12904-12913, doi:10.1523/JNEUROSCI. 2531-06.2006

15. Munschauer FE 3rd, Kinkel RP (1997) Managing side effects of interferon-beta in patients with relapsing-remitting multiple sclerosis. Clin Ther 19:883-893

16. Perini P, Calabrese M, Biasi G, Gallo P (2004) The clinical impact of interferon beta antibodies in relapsing-remitting MS. J Neurol 251:305-309, doi:10.1007/s00415-004-0312-8

17. Scheu S, Dresing P, Locksley RM (2008) Visualization of IFNbeta production by plasmacytoid versus conventional dendritic cells under specific stimulation conditions in vivo. Proc Natl Acad Sci U S A 105:20416-20421, doi:10.1073/pnas.0808537105

18. Erlandsson L, Blumenthal R, Eloranta ML, Engel H, Alm G, Weiss S, Leanderson T (1998) Interferon-beta is required for interferon-alpha production in mouse fibroblasts. Curr Biol 8:223-226

19. Hwang SY, Hertzog PJ, Holland KA, Sumarsono SH, Tymms MJ, Hamilton JA, Whitty G, Bertoncello I, Kola I (1995) A null mutation in the gene encoding a type I interferon receptor component eliminates antiproliferative and antiviral responses to interferons alpha and beta and alters macrophage responses. Proc Natl Acad Sci U S A 92:11284-11288

20. Sobottka B, Ziegler U, Kaech A, Becher B, Goebels N (2011) CNS live imaging reveals a new mechanism of myelination: the liquid croissant model. Glia 59:1841-1849, doi:10.1002/glia.21228

21. Ponomarev ED, Shriver LP, Maresz K, Dittel BN (2005) Microglial cell activation and proliferation precedes the onset of CNS autoimmunity. J Neurosci Res 81:374-389, doi:10.1002/jnr.20488

22. Norton WT, Poduslo SE (1973) Myelination in rat brain: method of myelin isolation. J Neurochem 21:749-757

23. Blasi E, Barluzzi R, Bocchini V, Mazzolla R, Bistoni F (1990) Immortalization of murine microglial cells by a v-raf/v-myc carrying retrovirus. J Neuroimmunol 27:229-237

24. Bocchini V, Mazzolla R, Barluzzi R, Blasi E, Sick P, Kettenmann H (1992) An immortalized cell line expresses properties of activated microglial cells. J Neurosci Res 31:616-621, doi:10.1002/jnr.490310405

25. Aktas O, Smorodchenko A, Brocke S, Infante-Duarte C, Schulze Topphoff U, Vogt J, Prozorovski T, Meier S, Osmanova V, Pohl E, Bechmann I, Nitsch R, Zipp F (2005) Neuronal damage in autoimmune neuroinflammation mediated by the death ligand TRAIL. Neuron 46:421-432, doi:10.1016/j. neuron.2005.03.018

26. Dresing P, Borkens S, Kocur M, Kropp S, Scheu S (2010) A fluorescence reporter model defines "Tip-DCs" as the cellular source of interferon beta in murine listeriosis. PLoS One 5:e15567, doi:10.1371/journal. pone.0015567

27. Sierra A, Abiega O, Shahraz A, Neumann H (2013) Janus-faced microglia: beneficial and detrimental consequences of microglial phagocytosis. Front Cell Neurosci 7:6, doi:10.3389/fncel.2013.00006

28. Birgbauer E, Rao TS, Webb M (2004) Lysolecithin induces demyelination in vitro in a cerebellar slice culture system. J Neurosci Res 78:157-166, doi:10.1002/jnr.20248

29. Gitik M, Liraz-Zaltsman S, Oldenborg PA, Reichert F, Rotshenker S (2011) Myelin down-regulates myelin phagocytosis by microglia and macrophages through interactions between CD47 on myelin and SIRPalpha (signal regulatory protein-alpha) on phagocytes. J Neuroinflammation 8:24, doi:10.1186/1742-2094-8-24

30. Makranz C, Cohen G, Baron A, Levidor L, Kodama T, Reichert F, Rotshenker S (2004) Phosphatidylinositol 3-kinase, phosphoinositide-specific phospholipase-Cgamma and protein kinase-C signal myelin phagocytosis mediated by complement receptor-3 alone and combined with scavenger receptor-AI/II in macrophages. Neurobiol Dis 15:279-286, doi:10.1016/j. nbd.2003.11.007

31. Liu Y, Yang X, Guo C, Nie P, Liu Y, Ma J (2013) Essential role of MFG-E8 for phagocytic properties of microglial cells. PLoS One 8:e55754, doi:10.1371/ journal.pone.0055754

32. Thomas CA, Li Y, Kodama T, Suzuki H, Silverstein SC, El Khoury J (2000) Protection from lethal gram-positive infection by macrophage scavenger receptor-dependent phagocytosis. J Exp Med 191:147-156

33. Huynh KK, Eskelinen EL, Scott CC, Malevanets A, Saftig P, Grinstein S (2007) LAMP proteins are required for fusion of lysosomes with phagosomes. EMBO J 26:313-324, doi: 10.1038/sj.emboj.7601511

34. Skripuletz T, Hackstette D, Bauer K, Gudi V, Pul R, Voss E, Berger K, Kipp M, Baumgartner W, Stangel M (2013) Astrocytes regulate myelin clearance through recruitment of microglia during cuprizone-induced demyelination. Brain 136:147-167, doi:10.1093/brain/aws262

35. Isaksson M, Ardesjo B, Ronnblom L, Kampe O, Lassmann H, Eloranta ML, Lobell A (2009) Plasmacytoid DC promote priming of autoimmune Th17 cells and EAE. Eur J Immunol 39:2925-2935, doi:10.1002/eji.200839179

36. Asselin-Paturel C, Boonstra A, Dalod M, Durand I, Yessaad N, DezutterDambuyant C, Vicari A, O'Garra A, Biron C, Briere F, Trinchieri G (2001) Mouse type I IFN-producing cells are immature APCs with plasmacytoid morphology. Nat Immunol 2:1144-1150, doi:10.1038/ni736

37. Delhaye S, Paul S, Blakqori G, Minet M, Weber F, Staeheli P, Michiels T (2006) Neurons produce type I interferon during viral encephalitis. Proc Natl Acad Sci U S A 103:7835-7840, doi:10.1073/pnas.0602460103

38. Town T, Jeng D, Alexopoulou L, Tan J, Flavell RA (2006) Microglia recognize double-stranded RNA via TLR3. J Immunol 176:3804-3812

39. Ward LA, Massa PT (1995) Neuron-specific regulation of major histocompatibility complex class I, interferon-beta, and anti-viral state genes. J Neuroimmunol 58:145-155

40. van Heteren JT, Rozenberg F, Aronica E, Troost D, Lebon P, Kuijpers TW (2008) Astrocytes produce interferon-alpha and CXCL10, but not IL-6 or CXCL8, in Aicardi-Goutieres syndrome. Glia 56:568-578, doi:10.1002/ glia.20639

41. Traugott U, Lebon P (1988) Multiple sclerosis: involvement of interferons in lesion pathogenesis. Ann Neurol 24:243-251, doi:10.1002/ana.410240211

42. Imai Y, Ibata I, Ito D, Ohsawa K, Kohsaka S (1996) A novel gene iba1 in the major histocompatibility complex class III region encoding an EF hand protein expressed in a monocytic lineage. Biochem Biophys Res Commun 224:855-862, doi:10.1006/bbrc.1996.1112

43. Sedgwick JD, Schwender S, Imrich H, Dorries R, Butcher GW, ter Meulen V (1991) Isolation and direct characterization of resident microglial cells from the normal and inflamed central nervous system. Proc Natl Acad Sci U S A 88:7438-7442

44. Nimmerjahn A, Kirchhoff F, Helmchen F (2005) Resting microglial cells are highly dynamic surveillants of brain parenchyma in vivo. Science 308:1314-1318, doi:10.1126/science.1110647

45. Murphy AC, Lalor SJ, Lynch MA, Mills KH (2010) Infiltration of Th1 and Th17 cells and activation of microglia in the CNS during the course of experimental autoimmune encephalomyelitis. Brain Behav Immun 24:641-651, doi:10.1016/j.bbi.2010.01.014

46. Tanuma N, Sakuma H, Sasaki A, Matsumoto Y (2006) Chemokine expression by astrocytes plays a role in microglia/macrophage activation and subsequent neurodegeneration in secondary progressive multiple sclerosis. Acta Neuropathol 112:195-204, doi:10.1007/s00401-006-0083-7

47. Yamasaki R, Lu H, Butovsky O, Ohno N, Rietsch AM, Cialic R, Wu PM, Doykan CE, Lin J, Cotleur AC, Kidd G, Zorlu MM, Sun N, Hu W, Liu L, Lee JC, Taylor SE, Uehlein L, Dixon D, Gu J, Floruta CM, Zhu M, Charo IF, Weiner HL, Ransohoff RM (2014) Differential roles of microglia and monocytes in the inflamed central nervous system. J Exp Med 211:1533-1549, doi:10.1084/ jem.20132477

48. Mizutani M, Pino PA, Saederup N, Charo IF, Ransohoff RM, Cardona AE (2012) The fractalkine receptor but not CCR2 is present on microglia from embryonic development throughout adulthood. J Immunol 188:29-36, doi:10.4049/jimmunol.1100421

49. Saederup N, Cardona AE, Croft K, Mizutani M, Cotleur AC, Tsou CL, Ransohoff RM, Charo IF (2010) Selective chemokine receptor usage by central nervous system myeloid cells in CCR2-red fluorescent protein knock-in mice. PLoS One 5:e13693, doi:10.1371/journal. pone.0013693

50. Nayak D, Roth TL, McGavern DB (2014) Microglia development and function. Annu Rev Immunol 32:367-402, doi:10.1146/annurev-immunol032713-120240

51. Hosmane S, Tegenge MA, Rajbhandari L, Uapinyoying P, Kumar NG, Thakor N, Venkatesan A (2012) Toll/interleukin-1 receptor domain-containing adapter inducing interferon-beta mediates microglial phagocytosis of degenerating axons. J Neurosci 32:7745-7757, doi:10.1523/JNEUROSCI. 0203-12.2012

52. Kuhlmann T, Wendling U, Nolte C, Zipp F, Maruschak B, Stadelmann C, Siebert H, Bruck W (2002) Differential regulation of myelin phagocytosis by macrophages/microglia, involvement of target myelin, Fc receptors and activation by intravenous immunoglobulins. J Neurosci Res 67:185-190

53. Bauer J, Sminia T, Wouterlood FG, Dijkstra CD (1994) Phagocytic activity of macrophages and microglial cells during the course of acute and chronic 
relapsing experimental autoimmune encephalomyelitis. J Neurosci Res 38:365-375, doi:10.1002/jnr.490380402

54. Napoli I, Neumann H (2010) Protective effects of microglia in multiple sclerosis. Exp Neurol 225:24-28, doi:10.1016/j.expneurol.2009.04.024

55. Takahashi K, Prinz M, Stagi M, Chechneva O, Neumann H (2007) TREM2transduced myeloid precursors mediate nervous tissue debris clearance and facilitate recovery in an animal model of multiple sclerosis. PLoS Med 4: e124, doi:10.1371/journal.pmed.0040124

56. Kotter MR, Li WW, Zhao C, Franklin RJ (2006) Myelin impairs CNS remyelination by inhibiting oligodendrocyte precursor cell differentiation. J Neurosci 26:328-332, doi:10.1523/JNEUROSCI. 2615-05.2006

57. David S, Lacroix S (2003) Molecular approaches to spinal cord repair. Annu Rev Neurosci 26:411-440, doi:10.1146/annurev.neuro.26.043002.094946

58. Goldmann T, Prinz M (2013) Role of microglia in CNS autoimmunity. Clin Dev Immunol 2013:208093, doi:10.1155/2013/208093

\section{Submit your next manuscript to BioMed Central and take full advantage of:}

- Convenient online submission

- Thorough peer review

- No space constraints or color figure charges

- Immediate publication on acceptance

- Inclusion in PubMed, CAS, Scopus and Google Scholar

- Research which is freely available for redistribution 